\title{
A semi-analytical method for plate and grid structures
}

\author{
J. S. Kuang PhD, CEng, FICE, FIStructE and H. Zhang MSc, PhD
}

In current design practice, analysis of plate and grid structures in civil engineering, such as waffle slabs, ribbed plates and slab-girder bridges, is based largely on code-specified approximate methods, and deflections of these systems are rarely evaluated owing to the complexity of calculations. A semi-analytical method is presented for bending and deflection analyses of plate and grid structures subjected to vertical loads. The proposed approach is derived based on the finiteelement method and can be used to solve conveniently and effectively the problem of the stiffened plates with irregular shape and openings, in which far fewer unknown variables will be involved in comparison with the finite-element method and less computation time will be required by employing the analytical transformations instead of the traditional matrix inverse. It was shown from the numerical investigations that the proposed method provided an efficient, yet accurate, means of analysing the stiffened plates. The results of the proposed approach for the example structures show good agreement with those from the finite-element method and experiments.

\section{NOTATION}

$\overline{\mathrm{f}}^{\mathrm{e}} \quad$ element generalised force vector

$\overline{\mathrm{K}}^{\mathrm{e}} \quad$ element generalised stiffness matrix

$\overline{\mathrm{K}}_{\mathrm{p}}^{\mathrm{e}} \quad$ plate stiffness matrix

$\overline{\mathrm{K}}_{\mathrm{b}}^{\mathrm{e}} \quad$ beam stiffness matrix

$l \quad$ length of the nodal line

$N \quad$ number of nodes

$\mathrm{N}$ shape function

$\mathrm{T}_{\mathrm{C}} \quad$ transformation matrix

V nodal line displacement

$\mathrm{V}^{\mathrm{s}} \quad$ strip displacement vector

$W \quad$ displacement

$X_{\mathrm{m}}(\xi)$ displacement base functions of the nodal line

$\boldsymbol{\delta}^{\mathrm{e}} \quad$ element displacement vector for plates

$\xi \quad$ local coordinate of the $i$ th node on the nodal line

$\Phi_{n}(\xi)$ displacement base functions of the nodal line

\section{INTRODUCTION}

Plate and grid structures, such as waffle slabs, ribbed plates and bridge slab-girders are widely used in civil engineering practice, as they can span relatively long distances in comparison with the normal one-way and two-way beam and slab systems. In design practice, the analysis of plate and grid structures has mainly relied on code-specified approximate methods, and the deflections of a plate and grid structure are rarely evaluated owing to the complexity of the calculations. In general, procedures for the analysis and design for plate-andgrid structures are based largely on simplifications, in which the plate and grid are separated and the slab is simply supported by the grid. In addition, these approximate methods of analysis are most appropriate for uniform or quasi-uniform structures. For an irregular plate and grid system, it is necessary to use a more sophisticated model to conduct a precise analysis.

Yettram and Husain ${ }^{1}$ proposed an interesting method to represent a plate by a grillage system in which the beams are only arranged orthogonally. An equivalent orthotropic plate model has been developed by Troitsky ${ }^{2}$ and Harik and Salamoun, ${ }^{3}$ and has been widely used to analyse a stiffened isotropic slab with uniform thickness, while the contribution of the stiffeners is considered by modifying the plate rigidity in the stiffener directions. However, this model is not able to predict the actual behaviour of the stiffened plates with stiffeners that are relatively light or closely spaced. Further to the equivalent orthotropic plate model, a semi-discrete platebeam finite-element formulation has been proposed for the analysis of stiffened plates by Guo et al., ${ }^{4}$ with practical applications to the analysis of slab-girder bridges. In this method, the extensional displacements in the plate and beam elements caused by interaction between the plate and stiffener are presented in terms of the rotations and constant eccentricities, which are evaluated by assuming the plate as a multi T-section in each stiffener direction. This semi-discrete finite-element model has the potential for analysing complex plate structures to eliminate the need for the plate degrees of freedom. This simplified method is not suitable, however, for stress computations since the assumptions made do not hold in the neighbourhood of the attachment of the stiffeners to slabs.

In the present study, a semi-analytical method was devised for the analysis of plate and grid structures in buildings and bridges, in which the plate and grid structure was modelled as an analogous stiffened plate. The proposed approach was derived from the finite-element method and can be used to solve conveniently and effectively the problem of stiffened plates with irregular shape and openings, but involving far fewer unknown variables in comparison with the finite-element method. In addition, less computation time was required using 
the proposed analytical transformations instead of the traditional matrix inverse. It can be seen from the numerical investigations that the proposed method provided an efficient, yet accurate, means for analysing the stiffened plates. The results of the proposed analyses for the example structures showed very good agreement with those from the finiteelement method and experiments.

\section{ANALYSIS}

A general plate and grid structure consisting of slabs and beams is shown in Fig. 1. The structure can conveniently be considered as a stiffened plate with the combination of plate panels (slabs) and grids (stiffeners/beams). Since the skeleton of grids is basically a naturally strip-like system, the analogous stiffened plate is always divided into a number of strips by nodal lines, such as lines $L$ and $L^{\prime}$ shown in Fig. 1; while the openings, material discontinuities and arbitrary orientated stiffeners may be placed anywhere within the strips. The strips will later be discretised into triangular or quadratic plate elements according to the given geometry information.

\section{I. Nodal line displacement}

In the finite-element analysis, each individual vertex of elements can generally be treated as an independent node. Degrees of freedom of the nodes are considered as unknown

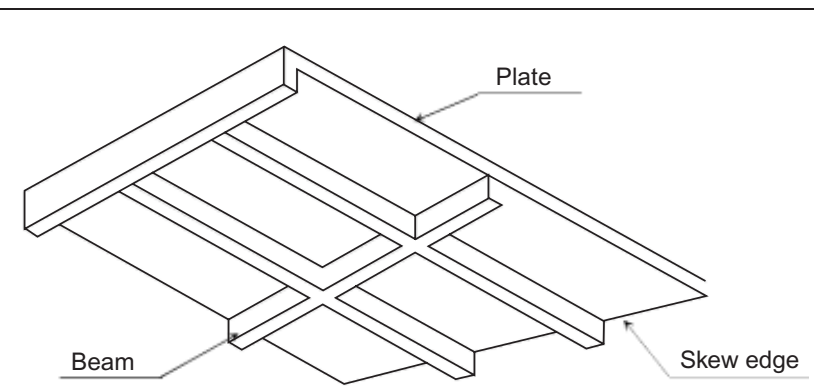

(a)

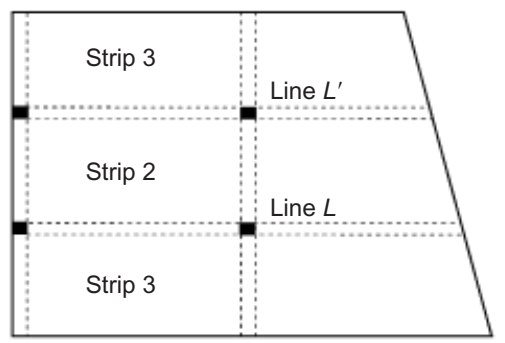

(b)

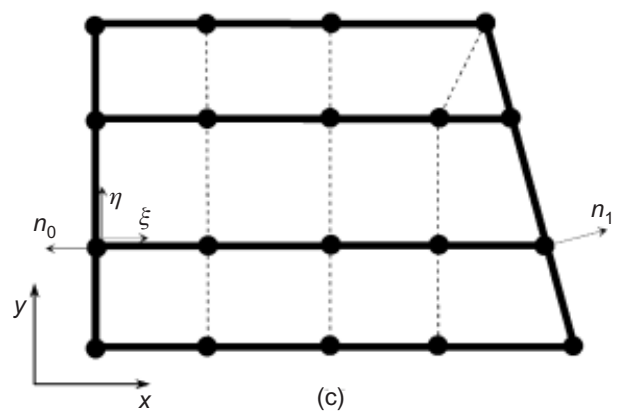

Fig. I. An analogous stiffened plate for general plate and grid structures: (a) isometric view; (b) plane layout; (c) discretised mesh variables accordingly when assembling the global simultaneous equations. The storage and computation cost for solving this problem will thus become enormous, when the joint number of the structure is very large. However, this can be overcome to utilise the intrinsic affiliation for reducing the number of the unknown variables, since the nodes on the same nodal line are related to each other.

Consider line $L$ in Fig. 1. The displacement along the line can be expressed by

$\left\{\begin{array}{l}w_{i}=\sum_{m=1}^{r} a_{m} X_{m}\left(\xi_{i}\right) \\ \left(\frac{\partial w}{\partial \xi}\right)_{i}=\sum_{m=1}^{r} a_{m} X_{m}^{\prime}\left(\xi_{i}\right) \\ \left(\frac{\partial w}{\partial \eta}\right)_{i}=\sum_{n=1}^{p} b_{n} \Phi_{n}\left(\xi_{i}\right)+\theta_{0}\left(1-\frac{\xi_{i}}{l}\right)+\theta_{1}\left(\frac{\xi_{i}}{l}\right) \\ \text { for } i=1,2, \ldots, N\end{array}\right.$

where $\xi_{i}$ is the local coordinate of the $i$ th node on the nodal line; $N$ is the number of nodes; $l$ is the length of the nodal line; and $X_{m}(\xi)$ and $\Phi_{n}(\xi)$ are the displacement base functions of the nodal line. They must satisfy the requirements of boundary constraint at the ends of the line. Parameters $a_{m}$ and $b_{n}$ are used to describe directly the nodal line displacements; rotations $\theta_{0}$ and $\theta_{1}$ are defined as

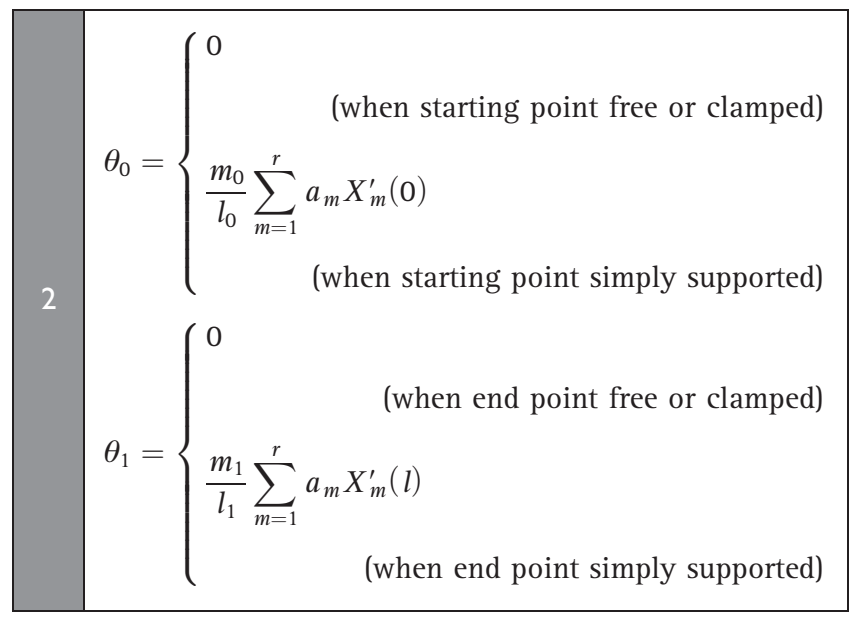

in which

\begin{tabular}{c}
$l_{0}=\frac{\left|\bar{n}_{0} \times \bar{\xi}\right|}{\left|\bar{n}_{0}\right| \times|\bar{\xi}|}, \quad m_{0}=\frac{\left|\bar{n}_{0} \times \bar{\eta}\right|}{\left|\bar{n}_{0}\right| \times|\bar{\eta}|}$, \\
$l_{1}=\frac{\left|\bar{n}_{1} \times \bar{\xi}\right|}{\left|\bar{n}_{1}\right| \times|\bar{\xi}|}$ and $m_{1}=\frac{\left|\bar{n}_{1} \times \bar{\eta}\right|}{\left|\bar{n}_{1}\right| \times|\bar{\eta}|}$ \\
\hline
\end{tabular}

From equations (2) and (3) it can be seen that when a nodal line is perpendicular to the boundary, $m_{0}=m_{1}=0$, and thus $\theta_{0}=\theta_{1}=0$. It is also seen that if the nodal line forms a skew angle with a simply supported boundary, tangentially rotational angles of the line at the boundary are equal to zero. 


\subsection{Boundary restraints}

The displacement base functions, $X_{m}(\xi)$ and $\Phi_{n}(\xi)$, are significantly influenced by the boundary restraints. At the starting point of a nodal line ( $\xi=0)$, the restraints for different boundary conditions are as follows.

(a) When the point is clamped, $w=0, \partial w / \partial \xi=0$ and $\partial w / \partial \eta=0$. The displacement boundary conditions are given by

\begin{tabular}{|c|c|}
\hline 4 & $X_{m}(0)=X_{m}^{\prime}(0)=0 \quad(m=1,2, \ldots, r)$ \\
& $\Phi_{n}(0)=0 \quad(n=1,2, \ldots, p)$ \\
\hline
\end{tabular}

(b) When the point is simply supported, $\mathrm{w}=0$ and $-(\partial w / \partial \xi) m_{0}+(\partial w / \partial \eta) l_{0}=0$. The displacement boundary conditions are given by

\begin{tabular}{|c|cc|}
\hline 5 & $X_{m}(0)=0 \quad(m=1,2, \ldots, r)$ \\
& $\Phi_{n}(0)=0 \quad(n=1,2, \ldots, p)$ \\
\hline
\end{tabular}

(c) When the point is free, functions of $w, \partial w / \partial \xi$ and $\partial w / \partial \eta$ are related to free edge boundary conditions; thus there is no boundary restraint in the base functions, $X_{m}(0), X_{m}^{\prime}(0)$ and $\Phi_{n}(0)$.

It is assumed that the approximate deformed profiles of nodal lines are known. Hence the base functions $X_{m}(\xi)$ and $\Phi_{n}(\xi)$ will govern the profiles of deformation and should fulfil the boundary conditions at both ends. The parameters $a_{m}$ and $b_{n}$ will be used to determine the exact deflected shapes, thus becoming unknown variables instead of the node displacements. Consequently, the number of unknown variables can be reduced significantly.

\section{TRANSFORMATION}

In the proposed analysis, the shape functions of the beam in bending are selected as the base functions of the nodal line. In order to obtain the displacement of each node in nodal lines, the unknown variables $a_{m}$ and $b_{n}$ are determined by solving the simultaneous equations about $a_{m}$ and $b_{n}$, which are developed through a new transformation technique. In the proposed technique, two transformation steps are needed in the analysis. The transformation at the nodal line level should be conducted first; the transformation at the element level is then carried out with an assembly of the nodal transformations.

\section{I. Transformation from node displacement to nodal line displacement}

Consider a typical strip of a stiffened plate shown in Fig. 2. For the sake of brevity, the two nodal lines are assumed to be parallel to $x$-axis. The origin of the local coordinate system is

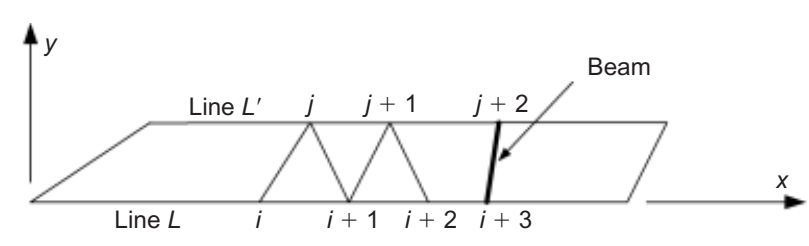

Fig. 2. A typical strip set at one of the ends of the nodal line $L$ and the $x$-axis passes through this nodal line, as shown in Fig. 2.

The base function expressed by equation (1) can be written as

$\left\{\begin{array}{l}w_{i}=\sum_{m=1}^{r} a_{m} X_{m}\left(x_{i}\right) \\ \left(\frac{\partial w}{\partial x}\right)_{i}=\sum_{m=1}^{r} a_{m} X_{m}^{\prime}\left(x_{i}\right) \\ \left(\frac{\partial w}{\partial y}\right)_{i}=\sum_{n=1}^{p} b_{n} \Phi_{n}\left(x_{i}\right)+\theta_{0}\left(1-\frac{x_{i}}{l}\right)+\theta_{1}\left(\frac{x_{i}}{l}\right)\end{array}\right.$

The $i$ th node displacement on the $l$ th nodal line is

\begin{tabular}{|l|l}
\hline 7 & {$\left[\delta_{i}\right]=\left\{w_{i}, \quad\left(\frac{\partial w}{\partial x}\right)_{i},\left(\frac{\partial w}{\partial y}\right)_{i}\right\}$} \\
\hline
\end{tabular}

The nodal line displacement vector is then given by

$$
8 \quad\left[\delta^{l}\right]=\left\{\left[\delta_{1}\right],\left[\delta_{2}\right], \ldots,\left[\delta_{N}\right]\right\}
$$

When the generalised nodal line displacement vector is expressed as

$$
\mathrm{V}^{l}=\left\{a_{1}, a_{2}, \ldots, a_{r}, b_{1}, b_{2}, \ldots, b_{p}\right\}
$$

equation (6) can be written in a matrix form as

$$
10 \quad\left[\delta_{i}\right]=\mathrm{T}_{i} \mathrm{~V}^{l}
$$

where the transformation matrix is given by

| $\quad \mathrm{T}_{i}=\left[\begin{array}{lllll}X_{1}\left(x_{i}\right) & X_{2}\left(x_{i}\right) & \cdots & X_{r}\left(x_{i}\right) & 0 \\ & & 0 & 0 \\ X_{1}^{\prime}\left(x_{i}\right) & X_{2}^{\prime}\left(x_{i}\right) & \cdots & X_{r}^{\prime}\left(x_{i}\right) & 0 \\ & & 0 & 0 & \\ C_{1}\left(x_{i}\right) & C_{2}\left(x_{i}\right) & \cdots & C_{r}\left(x_{i}\right) & \Phi_{1}\left(x_{i}\right) \\ & & \Phi_{2}\left(x_{i}\right) \cdots & \Phi_{p}\left(x_{i}\right)\end{array}\right]$

in which the function $C_{k}\left(x_{i}\right)(k=1,2, \ldots, r)$ is determined by the boundary constraint conditions of the nodal line, given by

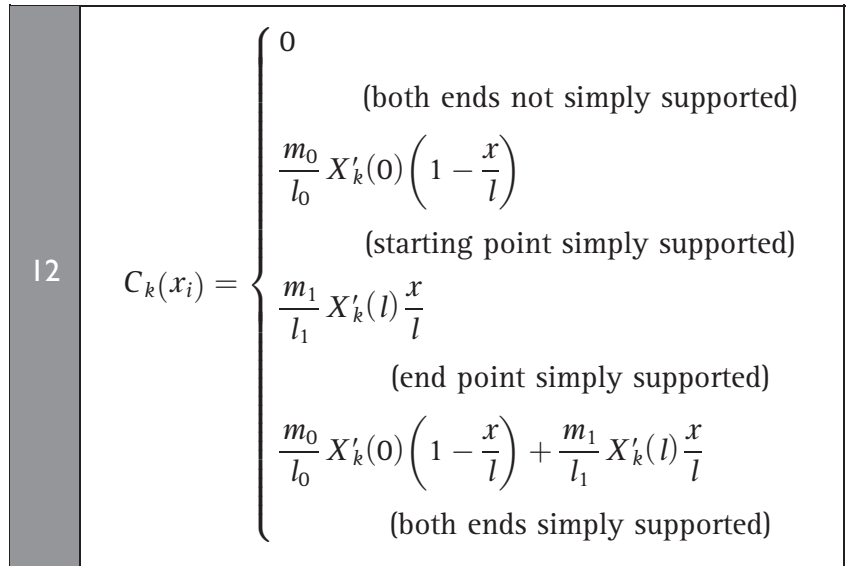


Equation (10) presents the relationship between the node displacement $\left[\delta_{i}\right]$ and the nodal line displacement vector $\mathrm{V}^{\mathrm{l}}$. Hence, the transformation at the element level, namely the transformation of node displacement to nodal line displacement, can be conducted using equation (10), which is in fact a process of the assembly of the transformations at the nodal line level.

\subsection{Transformation from node displacement to strip displacement}

After deriving the relationship between the node displacement and the nodal line displacement vector, the stiffness matrix and force vector need to be transformed accordingly. In order to transform the stiffness matrix and force vector, the relationship between the displacements of nodes and strips is derived and expressed by

\section{3}

$$
\boldsymbol{\delta}^{\mathrm{e}}=\mathrm{T}_{\mathrm{e}} \mathrm{V}^{s}
$$

where $\boldsymbol{\delta}^{\mathrm{e}}$ is the element displacement vector for plates or beams, $T_{e}$ is the transformation matrix and the strip displacement vector $\mathrm{V}^{\mathrm{s}}$ is given by

\section{4}

$$
\mathrm{V}^{\mathrm{s}}=\left\{\mathrm{V}^{l}, \mathrm{~V}^{l+1}\right\}
$$

In the finite-element analysis, the most commonly used elements in the plate discretisation are triangular and quadrilateral ones. In the triangular and quadrilateral elements shown in Fig. 3, vertexes $i$ and $j$ are located at the nodal line $l$, while vertexes $j^{\prime}$ and $k^{\prime}$ are located at the nodal line $l^{\prime}$. The displacement vectors of the triangular and quadrilateral elements and the corresponding transformation matrices are given, respectively, by

15

$$
\boldsymbol{\delta}^{\mathrm{e}}=\left\{\delta_{i}, \delta_{j}, \delta_{k}\right\} \text { and } \mathrm{T}_{\mathrm{e}}=\left[\begin{array}{cc}
\mathrm{T}_{i} & 0 \\
0 & \mathrm{~T}_{j^{\prime}} \\
0 & \mathrm{~T}_{k^{\prime}}
\end{array}\right]
$$

Beam elements can be located in different ways in a strip, as shown in Fig. 4, either along the nodal line or across two nodal lines. For these two cases, the displacement vectors and the corresponding transformation matrices are given, respectively, by
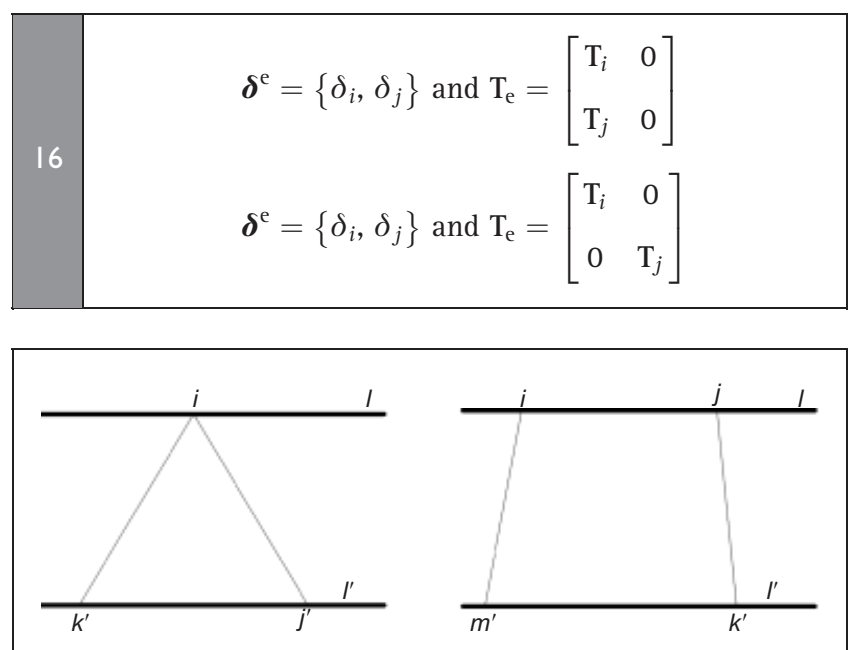

Fig. 3. Commonly used elements in a plate discretisation

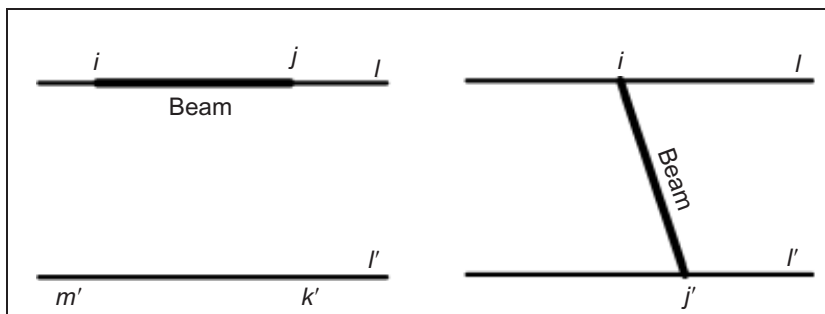

Fig. 4. Arrangement of beam element in a strip

In the proposed analysis, equation (13) is conveniently used for the transformation of node displacement to strip displacement. By following the standard procedure of the displacement discretisation in the finite-element method, the original simultaneous equations for nodes can be transformed to the simultaneous equations for the generalised strip displacements.

\section{GENERALISED STIFFNESS MATRIX AND FORCE VECTOR}

Once the relationship between the node displacement and the generalised strip displacement is developed, the discretisation for determining the stiffness matrixes and force vectors can be conducted. In the finite-element method, the internal virtual

\begin{tabular}{|c|c|}
\hline 17 & $\begin{aligned} \delta \mathrm{II}= & \delta \mathrm{II}_{p}+\delta \mathrm{II}_{b} \\
= & \int_{\Omega} \delta w(\mathbf{L} \nabla)^{\mathrm{T}} \mathbf{D}(\mathbf{L} \nabla) w \mathrm{~d} \Omega \\
& +\frac{1}{2} \sum_{i} \int_{0}^{l}\left(E I \frac{\partial^{2} w}{\partial s^{2}}+G J \frac{\partial^{2} w}{\partial s \partial n}\right) \mathrm{d} x\end{aligned}$ \\
\hline
\end{tabular}
work for a stiffened plate with stiffening beams of three degrees of freedom is given by

The discretisation is expressed as

\begin{tabular}{|l|l|}
\hline$w=N \boldsymbol{\delta}^{\mathrm{e}}$ \\
\hline
\end{tabular}

or from equation (13)

18

$8=\mathrm{NT}_{\mathrm{e}} \mathrm{V}^{\mathrm{s}}$

where $\mathrm{N}$ is the shape function.

Substituting equation (18) into equation (17) yields

$$
19 \quad \overline{\mathrm{K}}^{\mathrm{e}} \mathrm{V}^{\mathrm{s}}=\overline{\mathrm{f}}^{\mathrm{e}}
$$

where $\overline{\mathrm{K}}^{\mathrm{e}}$ and $\overline{\mathrm{f}}^{\mathrm{e}}$ are the element generalised stiffness matrix and force vector, respectively, with parameters $a_{m}$ and $b_{n}$. The element generalised stiffness matrix is

$$
20 \quad \overline{\mathbf{K}}^{\mathrm{e}}=\overline{\mathbf{K}}_{\mathrm{p}}^{\mathrm{e}} \oplus \overline{\mathbf{K}}_{\mathrm{b}}^{\mathrm{e}}
$$

in which $\overline{\mathrm{K}}_{\mathrm{p}}^{\mathrm{e}}$ and $\overline{\mathrm{K}}_{\mathrm{b}}^{\mathrm{e}}$ are the plate and beam stiffness matrices, respectively, and $\oplus$ denotes the element assembly. The plate stiffness matrix is generally given by 


$$
\overline{\mathrm{K}}_{\mathrm{p}}^{\mathrm{e}}=\mathrm{T}_{\mathrm{e}}^{\mathrm{T}} \mathrm{K}_{\mathrm{p}}^{\mathrm{e}} \mathrm{T}_{\mathrm{e}}
$$

where $\mathrm{K}_{\mathrm{p}}^{\mathrm{e}}=\int_{\Omega} \mathrm{B}^{\mathrm{T}} \mathrm{DBd} \Omega$ with $\mathrm{B}=(\mathrm{L} \nabla) \mathrm{N}$. The beam stiffness matrix is generally given by

\section{2}

$\overline{\mathrm{K}}_{\mathrm{b}}^{\mathrm{e}}=\mathrm{T}_{\mathrm{e}}^{\mathrm{T}} \mathrm{K}_{\mathrm{b}}^{\mathrm{e}} \mathrm{T}_{\mathrm{e}}$

where $\mathrm{K}_{\mathrm{b}}^{\mathrm{e}}=\mathrm{C}_{\mathrm{b}}^{\mathrm{T}} \mathrm{K}_{\mathrm{b}^{\prime}}^{\mathrm{e}} \mathrm{C}_{\mathrm{b}}$ with

$22 \mathrm{a} \quad \mathrm{K}_{\mathrm{b}^{\prime}}^{\mathrm{e}}=\frac{E I}{l^{3}}\left[\begin{array}{ccccccc}12 & & & & & \\ 0 & r l^{2} & & & \text { sym } & \\ -6 l & 0 & 4 l^{2} & & & \\ -12 & 0 & 6 l & 12 & & \\ 0 & -r l^{2} & 0 & 0 & r l^{2} & \\ -6 l & 0 & 2 l^{2} & 6 l & 0 & 4 l^{2}\end{array}\right]$

in which $r=J / 2(1+\mu), J$ is the torsion constant and $\mu$ is Poisson's ratio; $C_{b}=\left[\begin{array}{cc}\Lambda & 0 \\ 0 & \Lambda\end{array}\right]$, where

$$
\Lambda=\left[\begin{array}{ccc}
1 & 0 & 0 \\
0 & \cos (s, x) & \cos (s, y) \\
0 & \cos (s, y) & -\cos (s, x)
\end{array}\right]
$$

The element generalised force vector is given by

\begin{tabular}{|l|c|}
\hline 23 & $\overline{\mathrm{f}}^{\mathrm{e}}=\mathrm{T}_{\mathrm{e}}^{\mathrm{T}} \mathrm{f}^{\mathrm{e}}$ \\
\hline
\end{tabular}

where

$$
\mathrm{f}^{e}=\int_{\Omega} \mathrm{N}^{\mathrm{T}} q d \Omega+\int_{\Gamma}\left(\mathrm{N}_{n}^{\mathrm{T}} \bar{M}_{n}+\mathrm{N}_{\mathrm{s}}^{\mathrm{T}} \bar{M}_{n \mathrm{~s}}+\mathrm{N}^{\mathrm{T}} \bar{S}_{n}\right) \mathrm{d} \Gamma
$$

\section{NUMERICAL INVESTIGATIONS}

Based on the proposed semi-analytical approach, the procedure of computation for the analysis of a slab and grid system, which is modelled as a stiffened plate, is as follows.

(a) Divide the plate into several strips by nodal lines.

(b) Mesh each strip with triangular or quadrilateral elements and develop the element stiffness matrix and force vector.

(c) Execute the transformations.

(d) Assemble simultaneous equations of the nodal line displacement, and then solve the equations.

(e) Calculate node displacements, then determine the element displacements for plates and stiffeners.

(f) Determine internal forces of the structure.

To demonstrate the effectiveness and accuracy of the proposed method for analysing stiffened plates, four examples were investigated; they included a rectangular one-way ribbed plate, ${ }^{5}$ two square plates, one stiffened by two orthogonal beams ${ }^{6}$ and the other by four orthogonal beams, ${ }^{7}$ respectively, and an orthogonally stiffened rectangular slab with openings.

\section{I. Rectangular one-way ribbed plate}

A rectangular one-way ribbed plate with four fixed edges is shown in Fig. 5, where the stiffening ribs are evenly distributed along the $x$-direction. The plate was subjected to a uniformly distributed load of $58.8 \mathrm{kN} / \mathrm{m}^{2}$. The plate and ribs were made of aluminium, with Young's modulus of $69.58 \mathrm{kN} / \mathrm{mm}^{2}$ and Poisson's ratio of $0 \cdot 315$. The thickness of the plate was $2 \mathrm{~mm}$; the moment of inertia and torsion constant of the ribs were 37.46 and $52.36 \mathrm{~mm}^{4}$, respectively.

Figure 6 shows the mid-span $(y=400 \mathrm{~mm})$ vertical displacements of the ribbed plate. A comparison of the results of vertical displacements from the different methods was made and is given in Table 1. It can be seen from Fig. 6 and Table 1 that the results of the proposed method show very good agreement with the predictions from the finite-element analysis using the comprehensive finite-element package SAP $2000^{8}$ and the finite-difference method. ${ }^{5}$

\subsection{Fixed-edge stiffened plates}

Two fixed-edge square plates stiffened by two and four orthogonal beams, respectively, are shown in Fig. 7. Both plates were subjected to a uniformly distributed load of $48 \mathrm{kN} / \mathrm{m}^{2}$. The side length and thickness of the plates were $a=201.8 \mathrm{~mm}$ and $t=2.82 \mathrm{~mm}$, respectively. The moment of inertia and torsion constant of the beams for plate 1 (Fig. 7(a)) were 59.6 and $99.6 \mathrm{~mm}^{4}$, respectively, and for plate 2 (Fig. 7 (b)) they were $45 \cdot 1$ and $86 \cdot 1 \mathrm{~mm}^{4}$. The plates and beams were made of the same material with Young's modulus of $207 \cdot 37 \mathrm{kN} / \mathrm{mm}^{2}$ and Poisson's ratio of $0 \cdot 3$.

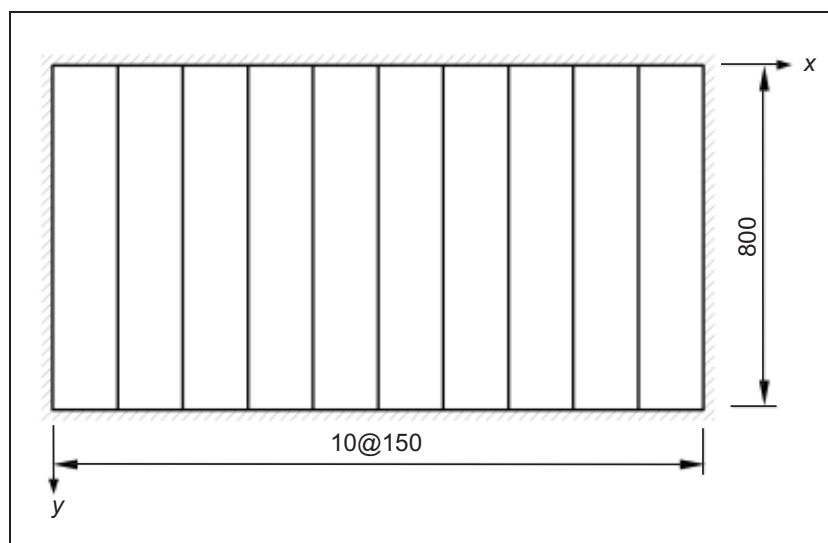

Fig. 5. Rectangular ribbed plate with fixed edges (unit: $\mathrm{mm}$ )

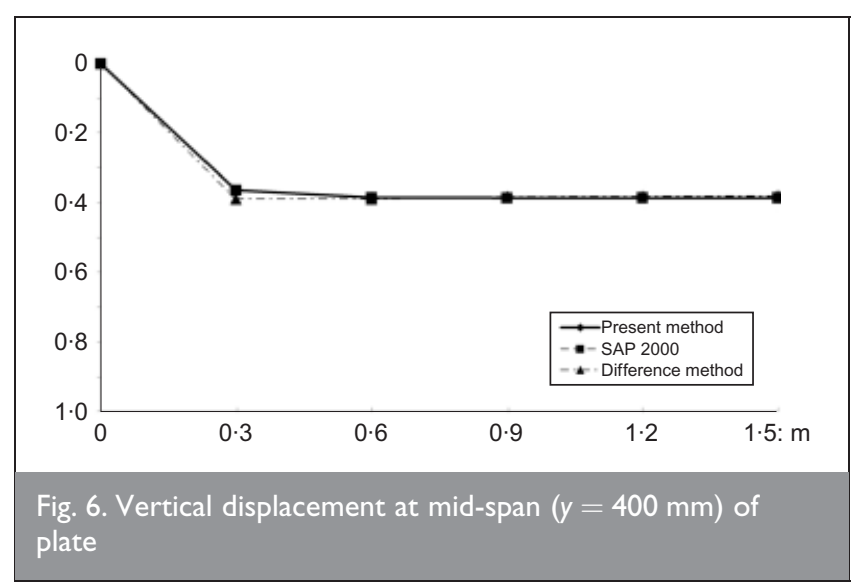




\begin{tabular}{|lccc|}
\hline Coordinate & Proposed & SAP $2000^{8}$ & Finite difference $^{5}$ \\
\hline$(150,400)$ & 0.3639 & 0.3639 & 0.3891 \\
$(300,400)$ & 0.3851 & 0.3857 & 0.3891 \\
$(450,400)$ & 0.3860 & 0.3861 & 0.3827 \\
$(600,400)$ & 0.3863 & 0.3860 & 0.3818 \\
$(750,400)$ & 0.3863 & 0.3860 & 0.3803 \\
& & & \\
Table I. Comparison of vertical displacements at mid-span \\
(unit: $\mathrm{mm})$
\end{tabular}

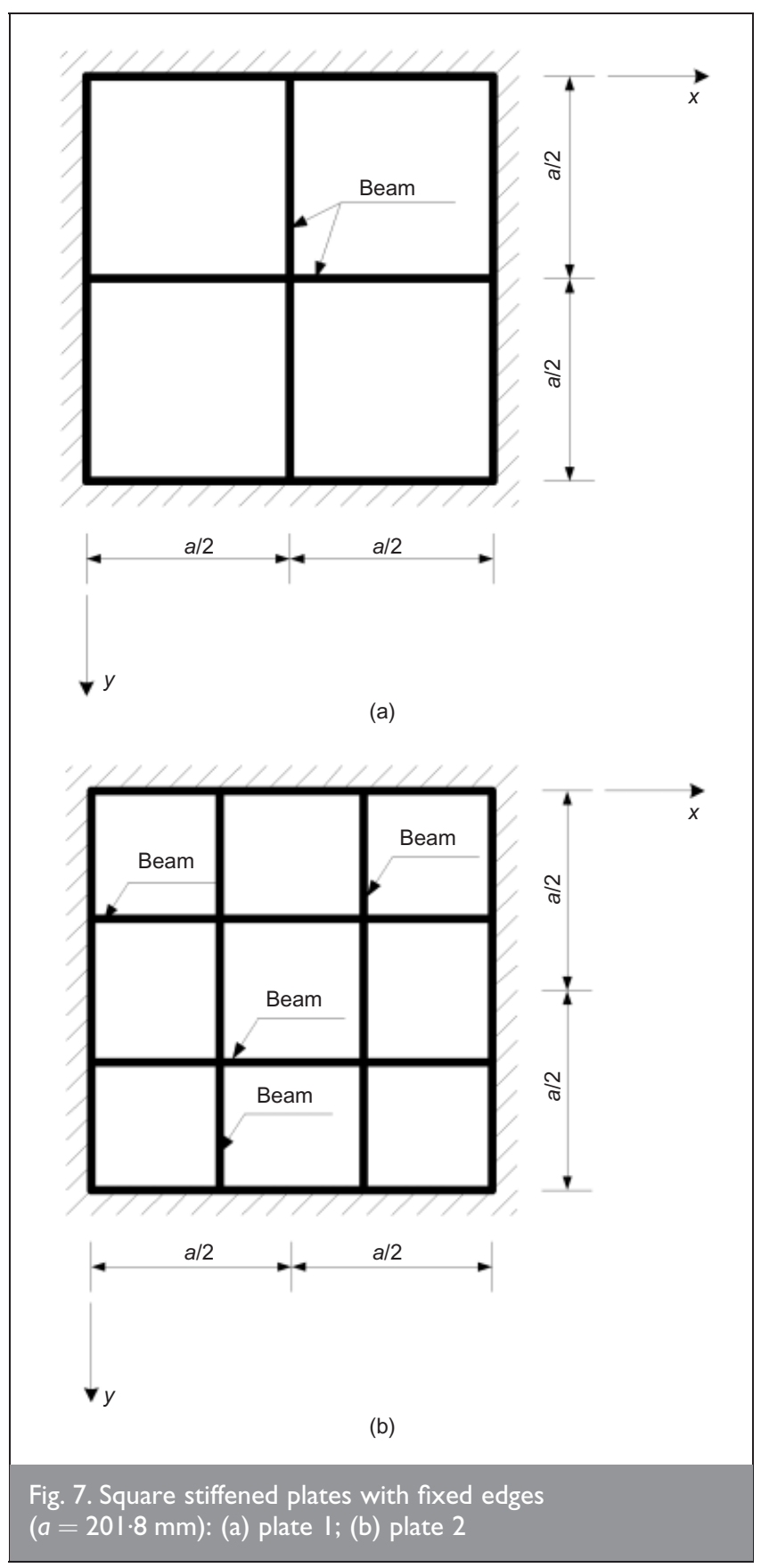

The vertical displacements and bending moments of plates 1 and 2 along the symmetrical axis $(y=a / 2)$ are shown in Figs 8 and 9, respectively. Comparisons of the results, which include the vertical displacements and bending moments of the plates and beams, derived by the different methods of analysis were made and the results presented in Tables 2 to 4 . It can be seen that the results of the proposed method agreed very well with those from the finite-element analysis and experiment.

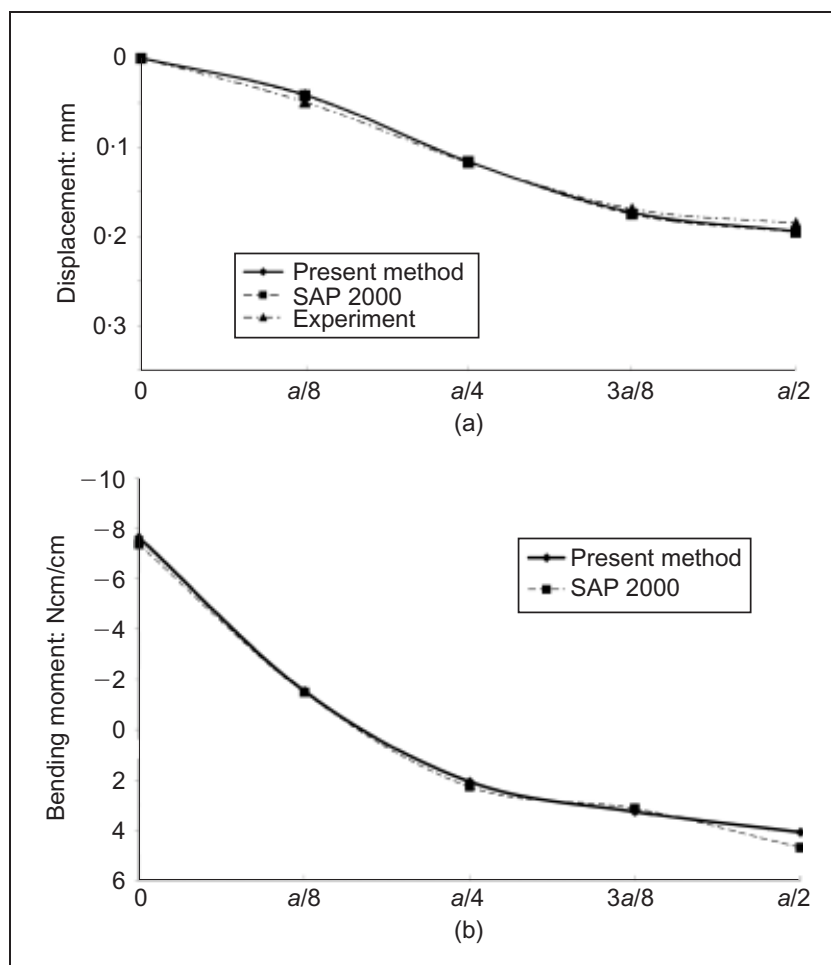

Fig. 8. Displacement and bending moment along symmetrical axis $(y=a / 2)$ of plate I: (a) vertical displacement in $x$-direction; (b) bending moment in $x$-direction

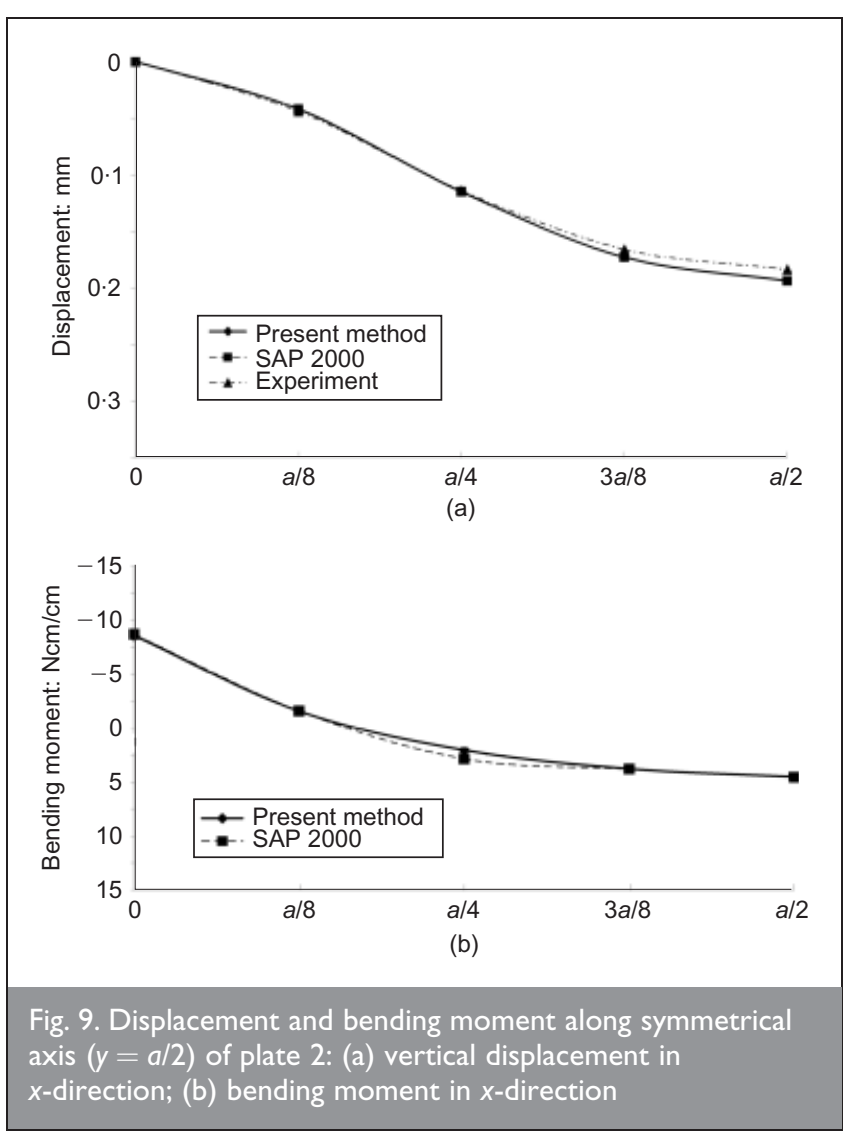




\begin{tabular}{|llll|}
\hline $\begin{array}{l}x \text {-coordinate: } \\
(a=201.8 \mathrm{~mm})\end{array}$ & Proposed & SAP 2000 & Experimental $^{6}$ \\
\hline 0 & 0 & 0 & 0 \\
$a / 8$ & 0.041 & 0.042 & 0.049 \\
$a / 4$ & 0.116 & 0.116 & 0.117 \\
$3 a / 8$ & 0.173 & 0.175 & 0.169 \\
$a / 2$ & 0.194 & 0.195 & 0.190 \\
& & & \\
Table 2. Comparison of vertical displacements along \\
symmetrical axis $(y=a / 2)$ from different methods for plate I \\
(unit: mm)
\end{tabular}

\begin{tabular}{|c|c|c|c|}
\hline $\begin{array}{l}x \text {-coordinate: } \\
(a=201.8 \mathrm{~mm})\end{array}$ & Proposed & SAP $2000^{8}$ & Experimental ${ }^{6}$ \\
\hline & \multicolumn{3}{|c|}{ Plate: $\mathrm{Ncm} / \mathrm{cm}$} \\
\hline 0 & -7.652 & $-7 \cdot 370$ & -7.927 \\
\hline$a / 8$ & -1.533 & -1.479 & - \\
\hline$a / 4$ & $2 \cdot 072$ & $2 \cdot 273$ & - \\
\hline $3 a / 8$ & $3 \cdot 266$ & $3 \cdot 133$ & - \\
\hline \multirow[t]{2}{*}{$a / 2$} & 4.090 & 4.699 & $3 \cdot 379$ \\
\hline & \multicolumn{3}{|c|}{ Beam: Ncm } \\
\hline 0 & $-21 \cdot 828$ & $-22 \cdot 345$ & -21.080 \\
\hline$a / 8$ & $-5 \cdot 263$ & -5.683 & -4.919 \\
\hline$a / 4$ & $4 \cdot 264$ & 3.704 & 3.973 \\
\hline $3 a / 8$ & $7 \cdot 585$ & $7 \cdot 563$ & 6.950 \\
\hline$a / 2$ & 8.596 & 8.537 & $7 \cdot 568$ \\
\hline
\end{tabular}

\begin{tabular}{|c|c|c|c|}
\hline $\begin{array}{l}x \text {-coordinate: } \\
(a=201.8 \mathrm{~mm})\end{array}$ & Proposed & SAP $2000^{8}$ & Experimental ${ }^{6}$ \\
\hline & \multicolumn{3}{|c|}{ Displacement: $\mathrm{mm}$} \\
\hline 0 & 0 & 0 & 0 \\
\hline$a / 8$ & 0.042 & 0.042 & 0.044 \\
\hline$a / 4$ & 0.115 & 0.115 & 0.114 \\
\hline $3 a / 8$ & 0.173 & 0.173 & 0.166 \\
\hline \multirow[t]{2}{*}{$a / 2$} & 0.194 & 0.194 & 0 \\
\hline & \multicolumn{3}{|c|}{ Bending moment: $\mathrm{Ncm}$} \\
\hline 0 & $-8 \cdot 554$ & -8.669 & $-8 \cdot 230$ \\
\hline$a / 8$ & -1.559 & $-1 \cdot 570$ & - \\
\hline$a / 4$ & 2.053 & 2.858 & - \\
\hline $3 a / 8$ & $3 \cdot 773$ & $3 \cdot 811$ & - \\
\hline$a / 2$ & 4.513 & 4.564 & 3.491 \\
\hline
\end{tabular}

\subsection{Slab and grid structure with openings}

A simply supported concrete slab and grid structure with two openings is shown in Fig. 10. The system can be considered as a stiffened plate, reinforced by two orthogonal beams. The slab carried a uniformly distributed load of $5 \mathrm{kN} / \mathrm{m}^{2}$ and a concentrated load of $100 \mathrm{kN}$ at the intersection (point E) of two

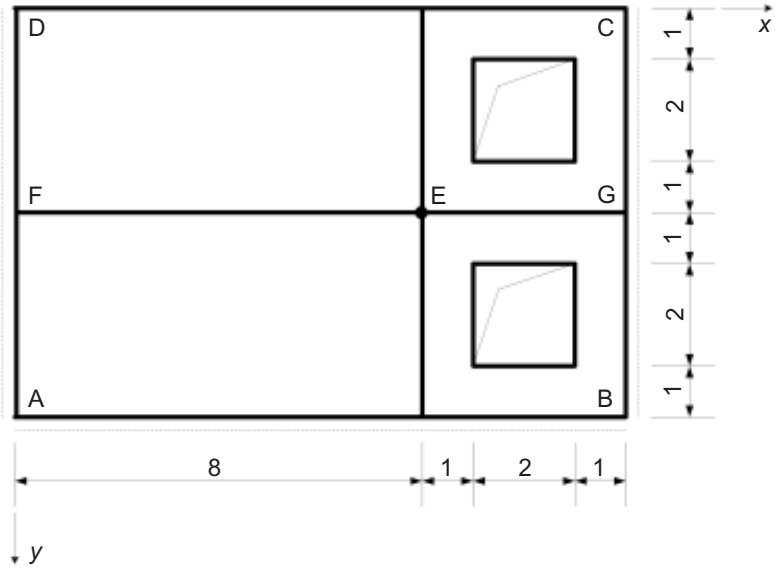

Fig. 10. A plate-and-grid structure with openings (unit: m)

beams. The thickness of the slab was $150 \mathrm{~mm}$ and the crosssection of the beams was $350 \mathrm{~mm} \times 500 \mathrm{~mm}$.

Despite the popular use of code-specified approximate approaches in the analysis of reinforced concrete slabs, the complexity of the structural behaviour of slabs with large openings has precluded the development of a satisfactory and effective method in practice. Instead, the proposed method provides an effective solution to such practical problems. Fig. 11 exhibits the mid-span vertical displacements of the slab in the $x$-direction. The comparison of results of vertical displacements from the proposed method and finite-element analysis is given in Table 5. It can be seen from Table 5 that the two sets of result agree very well.

\section{CONCLUSION}

A semi-analytical approach for the bending and deflection analysis of plate and grid structures in buildings, in which the plate and grid structure was modelled as an analogous stiffened plate, was followed in the present study. The proposed approach was derived from the finite-element method and can be used to solve the problem of the stiffened plates with irregular shape and openings, conveniently and effectively, but far fewer unknown variables were involved in comparison with the finite-element method, and it was simple to implement. The results of the proposed analyses for the example structures

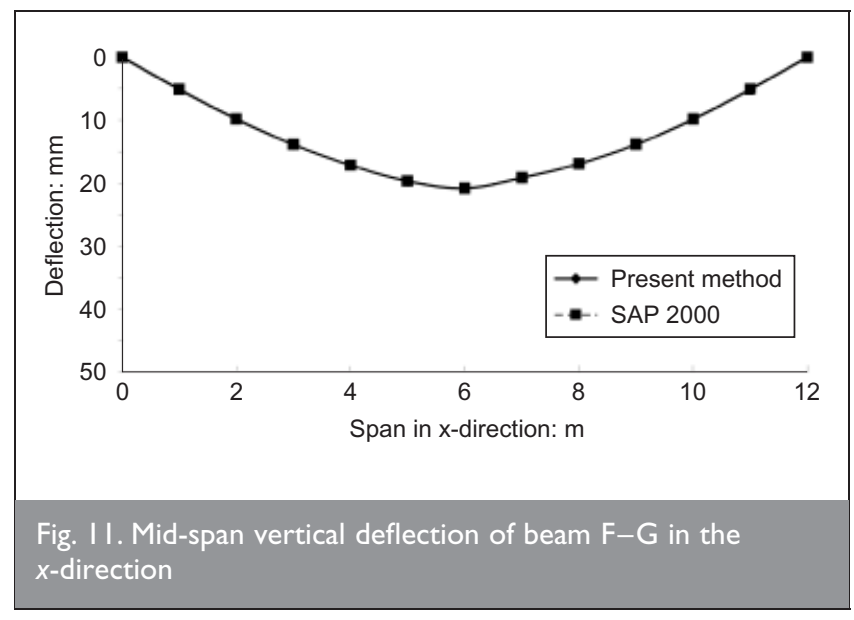




\begin{tabular}{|lcc|}
\hline Coordinate $(x, y): \mathrm{m}$ & Proposed: $\mathrm{mm}$ & SAP $2000^{8}: \mathrm{mm}$ \\
\hline$(1,4)$ & 5.52 & 5.11 \\
$(2,4)$ & 9.98 & 9.83 \\
$(3,4)$ & 13.71 & 13.89 \\
$(4,4)$ & 16.96 & 17.17 \\
$(5,4)$ & 19.41 & 19.69 \\
$(6,4)$ & 20.16 & 20.82 \\
$(7,4)$ & 19.04 & 19.15 \\
$(8,4)$ & 16.65 & 16.93 \\
$(9,4)$ & 13.72 & 13.87 \\
$(10,4)$ & 9.97 & 9.86 \\
$(11,4)$ & 5.51 & 5.11 \\
& & \\
Table 5. Comparison of mid-span vertical deflections of beam \\
F-G in the x-direction
\end{tabular}

\section{REFERENCES}

1. YetTRAm A. L. and Husain H. M. The representation of a plate in flexure by a grid of orthogonally connected beams. International Journal of Mechanical Sciences, 1965, 7, No. 4, $243-251$.

2. TroITSKY M. S. Stiffened Plates. Elsevier, New York, 1976.

3. HARIK I. E. and SALAMOUN G. An analytical strip method of solution for stiffened rectangular plates. Computers and Structures, 1988, 29, No. 2, 283-291.

4. Guo M. W., HariK I. E. and ReN W.-X. Semi-discrete finite element analysis of slab-girder bridges. Computers and Structures, 2002, 80, No. 23, 1789-1796.

5. SoNG T. Difference methods on static analysis of rectangular stiffened plates. Acta Mechanica Solida Sinica, 1986, 7, No. 1, 83-89.

6. SHEN P. C., HUANG D. and WANG Z. M. Static, vibration and stability analysis of stiffened plates using B-spline functions. Computers and Structures, 1987, 27, No. 1, 73-78.

showed good agreement with those from the finite-element method and the experiments. It was shown from the numerical examples that the proposed method provides a simple and efficient, yet accurate, means of analysing plate and grid structures.

7. SHEN P. C. The Finite Strip Method in Structure Analysis. Water Conservancy and Hydropower Press, Beijing, 1992.

8. COMPUTER AND STRUCTURES, INC. SAP 2000 version 9: Integrated Software for Structural Analysis and Design. Computer and Structures, Inc., Berkeley, CA, USA, 2005.

\section{What do you think?}

To comment on this paper, please email up to 500 words to the editor at journals@ice.org.uk

Proceedings journals rely entirely on contributions sent in by civil engineers and related professionals, academics and students. Papers should be 2000-5000 words long, with adequate illustrations and references. Please visit www.thomastelford.com/journals for author guidelines and further details. 